\title{
Urinary and sexual outcomes in long-term $(5+$ years) prostate cancer disease free survivors after radical prostatectomy
} Mauro Gacci*1, Alchiede Simonato ${ }^{2}$, Lorenzo Masieri1, John L Gore ${ }^{3}$, Michele Lanciotti ${ }^{1}$, Annalisa Mantella ${ }^{1}$, Mario Alberto Rossetti ${ }^{1}$, Sergio Serni ${ }^{1}$, Virginia Varca ${ }^{2}$, Andrea Romagnoli ${ }^{2}$, Carlo Ambruosi², Fabio Venzano ${ }^{2}$, Marco Esposito ${ }^{2}$, Tomaso Montanaro², Giorgio Carmignani ${ }^{2}$ and Marco Carini ${ }^{1}$

Address: ${ }^{1}$ Department of Urology, University of Florence, Careggi Hospital, Florence, Italy, 2 "L. Giuliani" Department of Urology, University of Genoa, Genoa, Italy and ' ${ }^{2}$ Department of Urology, David Geffen School of Medicine at UCLA, Los Angeles, CA, USA

Email: Mauro Gacci* - maurogacci@yahoo.it; Alchiede Simonato - asimonato@yahoo.it; Lorenzo Masieri - lmasieri@unifi.it; John L Gore - JLgore@ucla.com; Michele Lanciotti - mickeylanc@yahoo.com; Annalisa Mantella - amante@yahoo.it; Mario Alberto Rossetti - mrossetti@yahoo.it; Sergio Serni - sserni@unifi.it; Virginia Varca - vvarca@unige.it;

Andrea Romagnoli - aromagnoli@unige.it; Carlo Ambruosi - cambruosi@unige.it; Fabio Venzano - fvenzano@yahoo.it; Marco Esposito - mesposito@unige.it; Tomaso Montanaro - tmontanaro@unige.it; Giorgio Carmignani - gcarmignani@unige.it; Marco Carini - carini@unifi.it

* Corresponding author

Published: 13 November 2009

Health and Quality of Life Outcomes 2009, 7:94 doi:10.1 186/1477-7525-7-94

This article is available from: http://www.hqlo.com/content/7///94

(c) 2009 Gacci et al; licensee BioMed Central Ltd.

This is an Open Access article distributed under the terms of the Creative Commons Attribution License (http://creativecommons.org/licenses/by/2.0), which permits unrestricted use, distribution, and reproduction in any medium, provided the original work is properly cited.
Received: 16 July 2009

Accepted: 13 November 2009

\begin{abstract}
Background: After long term disease free follow up (FUp) patients reconsider quality of life (QOL) outcomes. Aim of this study is assess QoL in prostate cancer patients who are disease-free at least 5 years after radical prostatectomy (RP).
\end{abstract}

Methods: 367 patients treated with RP for clinically localized $p C a$, without biochemical failure (PSA $\leq 0.2 \mathrm{ng} / \mathrm{mL}$ ) at the follow up $\geq 5$ years were recruited.

Urinary (UF) and Sexual Function (SF), Urinary (UB) and Sexual Bother (SB) were assessed by using UCLA-PCl questionnaire. UF, UB, SF and SB were analyzed according to: treatment timing (age at time of RP, FUp duration, age at time of FUp), tumor characteristics (preoperative PSA, TNM stage, pathological Gleason score), nerve sparing (NS) procedure, and hormonal treatment (HT).

We calculated the differences between 93 NS-RP without HT (group A) and 274 non-NS-RP or NS-RP with HT (group B). We evaluated the correlation between function and bother in group A according to follow-up duration.

Results: Time since prostatectomy had a negative effect on SF and a positive effect SB (both $p<$ $0.00 I)$. Elderly men at follow up experienced worse UF and $S F(p=0.02$ and $p<0.00 I)$ and better $\mathrm{SB}(\mathrm{P}<0.001)$.

Higher stage PCa negatively affected UB, SF, and SB (all: $p \leq 0.05$ ). NS was associated with better UB, SF and SB (all: $p \leq 0.05$ ); conversely, HT was associated with worse UF, SF and SB (all: $p \leq 0.05$ ). 
More than 8 years after prostatectomy SF of group A and B were similar. Group A subjects (NSRP without HT) demonstrated worsening SF, but improved SB, suggesting dissociation of the correlation between SF and SB over time.

Conclusion: Older age at follow up and higher pathological stage were associated with worse QoL outcomes after RP. The direct correlation between UF and age at follow up, with no correlation between UF and age at time of RP suggests that other issues (i.e: vascular or neurogenic disorders), subsequent to RP, are determinant on urinary incontinence. After NS-RP without HT the correlation between SF and SB is maintained for 7 years, after which function and bother appear to have divergent trajectories.

\section{Background}

Prostate cancer and its treatments are costly and significantly impact quantity and quality of life; moreover, most prostate cancer survivors receive a significant portion of their care as outpatients [1]. Radical prostatectomy, in addition to represent one of the best approach for long term cancer control in clinically localized PCa [2], has a remarkable impact on patient's quality of life (QoL). Although the primary goal of any innovative treatment for prostate cancer is to maximize life expectancy, both patients and clinicians are currently devoting more attention to the impact of current therapies on QoL outcomes [3]. For many patients, the QoL impact of treatment determines the therapy selection among the currently available approaches [4]. Toward that end, several new surgical developments have attempted to maximize QoL after prostatectomy [5].

Urinary incontinence and erectile dysfunction are the most prominent side effects of radical prostatectomy [6]. The severity of patient-reported symptoms can be very different from symptom-related bother. Several items can affect both symptoms and bother in different ways. Urinary and sexual symptoms and bother are usually dependent on age at the time of surgery [7]. In addition, after long-term disease-free follow-up, patients have a propensity to reconsider their QoL status [8], even if aging can worsen overall patient health. Moreover, patients with high-risk PCa may better tolerate long term adverse events than those with low-risk PCa. Finally, a bilateral nervesparing approach, as well as the requirement for postoperative hormone treatment, can be major determinants of sexual QoL after prostatectomy [9].

The aims of the present study are: 1) to assess QoL outcomes in prostate cancer survivors who are disease-free at least 5 years after radical prostatectomy, 2) to identify the primary determinants of long-term QoL, and 3) to evaluate the impact of nerve-sparing surgery without hormone therapy on long-term urinary and sexual outcomes.

\section{Methods}

\section{Study population}

Our study population was composed of patients who had undergone radical retropubic prostatectomy (RP) for PCa in 2 centers of excellence between 1995-2002. Patients included underwent RP with either a bilateral nerve (NS) or non-nerve sparing (non-NS) approach as primary therapy for clinically localized prostate cancer (cT1-cT2, N0, $\mathrm{M0})$, maintained a postoperative PSA $₫ 0.2 \mathrm{ng} / \mathrm{mL}$ with follow-up of at least 5 years, and completed our study questionnaire. The follow-up schedule included serum PSA assay every 3 months for the first year, then every 6 months for the following two years and yearly thereafter. Biochemical relapse was defined as evidence of PSA $>0.2$ $\mathrm{ng} / \mathrm{mL}$ at two consecutive measurements.

Informed consent was obtained from all subjects. This trial was carried out in accordance with the ethic principles of the Helsinki declaration (1996) and good clinical practice issues (1997) and was reviewed and approved by both the local ethics committee.

We excluded those with preoperative urinary incontinence (assessed by medical history, at time of hospitalization), those who received neoadjuvant or adjuvant radiotherapy, those with incomplete pre or postoperative data, those who underwent unilateral NS-RP or in whom the NS status could not be determined, with an inability to complete the questionnaire, and refusal to participate. Furthermore, patients without a partner or without a sexual activity in the year before prostatectomy were excluded from the study, to improve the assessment of the sexual bother outcomes.

Patients with preoperative PSA $\leq 10 \mathrm{ng} / \mathrm{ml}$, biopsy Gleason score $\leq 7$, age at diagnosis $\leq 70$ years, and preoperative IIEF score $\geq 20$ were selected for NS-RP. All patients treated with a NS-RP used several ED treatments (including vacuum device, penile injections, and recently PDE-5 inhibitors), used subsequently or in combined therapies, with the aim to preserve or recover their sexual function. 
All RP specimens were fixed in formalin, coated with India ink, weighed, and serially sectioned, staged, and graded according to the 2002 American Joint Committee on Cancer (AJCC) staging system.

Follow-up included serum PSA every 3 months for the first two years, every 6 months for the following three years, and yearly thereafter. Biochemical relapse was defined as PSA $>0.2 \mathrm{ng} / \mathrm{ml}$ on 2 consecutive measurements. Patients with biochemical recurrence were treated with adjuvant hormonal therapy (LHRH analog with or without anti-androgen) at time of biochemical relapse.

\section{HRQOL measures}

We used the validated Italian version of the UCLA Prostate Cancer Index (PCI) [10], that assesses urinary continence and sexual function and their impact on related bother. We directly interviewed patients face to face, and they completed the questionnaire in a self reported fashion. This questionnaire allows evaluation of the detailed symptoms as well as their corresponding bother. For this analysis, we focused on subject urinary and sexual function (UF and SF) and urinary and sexual bother (UB and SB). Responses were scored from 0 to 100 , with a higher score indicating better QoL.

\section{Statistical analysis}

We evaluated in the statistical analysis the correlation between function and bother and subject demographic and clinical characteristics with Pearson correlation coefficients. Variables that were significant on univariate analysis were incorporated into a linear regression model (forward, stepwise variable entry) for multivariate analysis of factors influencing the items to evaluate postoperative urinary and sexual QoL over time. SF and SB outcomes were evaluated for all patients $(n=367)$ and for those who underwent NS-RP without HT (Group A, n = 93). Differences at 4 follow-up times (5, 6-7, 8-9, and $\geq 10$ years) in UF, UB, SF and SB scores between Group A subjects and the other 274 subjects treated with non-NS-RP or NS-RP and subsequent HT (Group B) were assessed by using unpaired samples t-tests. Finally, we calculated the correlation between UF and UB and between SF and SB of subjects in Group A at the above mentioned 4 different follow-up intervals with Pearson correlation coefficients.

\section{Results}

\section{Patient characteristics}

We overall collected 367 questionnaires: 307 men presented a follow up time $>5$ years (mean 95.5 months, $\mathrm{r}$ : 61-156), while for the remaining 60 men follow up time was 5 years (60 months). Clinical presentation, pathological findings and follow up time of the whole population and both subgroups of 5 years amd more than 5 years follow up are listed in table 1 . Mean age at RP was 64.8 years (median 66, range 47-77) and mean follow-up time was 89.7 months (median 84, range 60-156). Sixty subjects $(16.3 \%)$ had follow-up of 5 years, 146 subjects $(39.8 \%)$

Table I: Clinical presentation and pathological findings of the 367 patients

\begin{tabular}{|c|c|c|c|}
\hline & Overall & F.up 5 yy & F.up $>5$ yy \\
\hline $\mathbf{N}^{\circ}$ of patients & 367 & 60 & 307 \\
\hline Mean age (years), (median, range) & $64.8(66,47-77)$ & $64.1(65,49-74)$ & $64.9(66,47-77)$ \\
\hline Mean follow up (months), (median, range) & $89.7(84,60-156)$ & 60 & $95.5(87,61-156)$ \\
\hline \multicolumn{4}{|l|}{ Follow up time: (years) $n$ (\%) } \\
\hline 5 & & $60(16.3)$ & \\
\hline $6-7$ & & & 146 (39.8) \\
\hline $8-9$ & & & $81(22.1)$ \\
\hline$>10$ & & & $80(21.8)$ \\
\hline $\begin{array}{c}\text { Pre-operative PSA (ng/ml) } \\
\text { mean (median, range) }\end{array}$ & $14.6(10.2,0.8-87)$ & $12.8(9,3.9-63)$ & $15(10.6,0.8-87)$ \\
\hline Pre-operative PSA (ng/ml) & $n(\%)$ & n (\%) & $n(\%)$ \\
\hline$<10$ & $165(45.0)$ & $34(56.6)$ & $13 \mid(42.7)$ \\
\hline $10-20$ & $134(36.5)$ & $17(28.3)$ & $121(39.4)$ \\
\hline$>20$ & $68(18.5)$ & $9(15.1)$ & $55(17.9)$ \\
\hline Specimen Gleason Score & $n(\%)$ & $\mathbf{N}(\%)$ & $n(\%)$ \\
\hline $2-6$ & $154(42.0)$ & $31(5 \mid .7)$ & $123(40.1)$ \\
\hline 7 & $146(39.8)$ & $19(31.7)$ & $127(4 \mid .3)$ \\
\hline $8-10$ & $67(18.2)$ & $10(16.6)$ & $57(18.6)$ \\
\hline Pathological stage (TNM 1997) & $n(\%)$ & $n(\%)$ & $n(\%)$ \\
\hline$T 2$ & $222(60.5)$ & $40(66.7)$ & $182(59.3)$ \\
\hline T3a & $77(21.0)$ & $13(21.6)$ & $64(20.8)$ \\
\hline$T 3 b$ & $59(16.1)$ & $6(10)$ & $53(17.3)$ \\
\hline $\mathrm{T} 4$ & $9(2.4)$ & $\mathrm{I}(1.7)$ & $8(2.6)$ \\
\hline \multirow[t]{2}{*}{ Nerve sparing } & $n(\%)$ & $n(\%)$ & $n(\%)$ \\
\hline & 125 & $24(19.2)$ & $101(80.8)$ \\
\hline
\end{tabular}


had 6-7 years follow-up, 81 subjects $(22.1 \%)$ had $8-9$ years follow-up, and 80 subjects $(21.8 \%)$ had follow-up beyond 10 years. Of the 367 subjects, mean preoperative PSA was $14.6 \mathrm{ng} / \mathrm{ml}$ (median 10.2, range 0.8-87): 165 $(45.0 \%)$ had a PSA $<10,134(36.5 \%)$ had a PSA between $10-20$, and 68 (18.5\%) had a PSA > $20 \mathrm{ng} / \mathrm{ml}$. Pathologic stage was T2 in 222 subjects $(60.5 \%)$, pT3a in 77 subjects $(21.0 \%)$, pT3b in 59 subjects $(16.1 \%)$ and pT4 in 9 subjects $(2.4 \%)$. Median pathological Gleason score was 7: 56 in 154 subjects $(42.0 \%), 7$ in 146 subjects $(39.8 \%)$, and $8-10$ in 67 subjects $(18.2 \%)$.

NS-RP was performed in 125 subject (34.1\%): 24/60 $(40 \%)$ patients with a follow up time of 5 years, and 101/ 307 (33\%) with a follow up time $>5$ years (see table 1 ), The remaining 242 subjects (65.9\%) underwent non-NSRP. Only recently (in the last 5 years) we used structured procedures, with inclusion/exclusion criteria and scheduled treatment protocols either of profilaxis and treatment of post prostatectomy ED. All patients with a follow up time $>5$ years did not undergo a structured rehabilitation protocol for ED: the starting timing of drugs administration was not the same, and in many cases men started ED treatment several months after surgery. Furthermore the treatment of ED was outlined with different devices (PDE5, PgE, vacuum), used subsequently or in combined therapies. On the contrary, the remaining 24 patients with a follow up time of 5 years (19.2\%) undergone a structured profilaxis for postprostatectomy ED [11]: at follow up time 10 patients were using PDE5-i, 9 PDE5-i plus PGE, 1 patient needed the use of a vacuum device and 4 patients did not use any aids at all. For the heterogeneous data from patients with follow up $>5$ years and the small population of men with 5 years follow up we avoided the stratified analyses according to the use of erectile aids.
Seventy-six subjects $(20.7 \%)$ received adjuvant HT. Overall, 93 patients (25.3\%, Group A) treated with NS-RP did not require HT, while 274 (74.7\%, Group B) underwent either non-NS-RP (242 patients, $88.3 \%$ ) or NS followed by HT (32 patients, $11.7 \%$ ).

\section{Univariate analysis}

On univariate analysis (Table 2), urinary function was worse in older subjects, with adverse tumor characteristics and hormone treatment likewise correlated with worse continence. Subjects with unfavorable tumor characteristics and under HT also reported worse UB scores, while those treated with NS-RP endorsed better UB compared with those undergoing non-NS surgery.

Treatment timing, tumor characteristics, and HT were all negatively correlated with SF on univariate analysis, while NS-RP was positively correlated with SF. Those with longer follow-up, older age at follow-up, and those treated with NS-RP had less sexual bother. Subject with higher pathological stage and those who received HT had worse SB.

\section{Multivariate analysis}

Multivariate analysis (Table 3) showed a significant positive correlation between follow-up duration and SB and an inverse correlation between age at follow-up and UF. Moreover, pathological stage negatively affected UB, SF, and SB. Multivariate analysis confirmed the positive effect of NS on UB and SB and corroborated the negative effect of HT on UF.

Sexual function and sexual bother after NS-RP without $H T$ Concerning sexual function and bother after NS-RP without hormonal treatment, sexual bother was not influ-

Table 2: Univariate analysis of the whole study sample with Pearson correlation coefficients

\begin{tabular}{|c|c|c|c|c|c|c|c|c|}
\hline \multirow[b]{2}{*}{$\begin{array}{c}\text { Pearson } r \\
\text { p-value }\end{array}$} & \multicolumn{3}{|c|}{ Timing } & \multicolumn{3}{|c|}{ Tumor characteristics } & \multirow[t]{2}{*}{ Nerve-sparing } & \multirow{2}{*}{$\begin{array}{c}\text { Hormone } \\
\text { therapy }\end{array}$} \\
\hline & Age at RP & $\begin{array}{l}\text { Follow-up } \\
\text { duration }\end{array}$ & Age at follow-up & PSA & T-stage & Gleason score & & \\
\hline UF & $\begin{array}{l}-0.093 \\
0.075\end{array}$ & $\begin{array}{l}-0.091 \\
0.080\end{array}$ & $\begin{array}{c}-0.119 \\
0.023\end{array}$ & $\begin{array}{c}-0.167 \\
0.001\end{array}$ & $\begin{array}{c}-0.139 \\
0.008\end{array}$ & $\begin{array}{l}-0.184 \\
0.001\end{array}$ & $\begin{array}{l}0.096 \\
0.066\end{array}$ & $\begin{array}{l}-0.131 \\
0.017\end{array}$ \\
\hline UB & $\begin{array}{l}-0.049 \\
0.348\end{array}$ & $\begin{array}{l}-0.079 \\
0.131\end{array}$ & $\begin{array}{l}-0.076 \\
0.145\end{array}$ & $\begin{array}{c}-0.142 \\
0.006\end{array}$ & $\begin{array}{l}-0.163 \\
0.002\end{array}$ & $\begin{array}{l}-0.156 \\
0.004\end{array}$ & $\begin{array}{l}0.117 \\
0.025\end{array}$ & $\begin{array}{l}-0.105 \\
0.055\end{array}$ \\
\hline SF & $\begin{array}{l}-0.247 \\
<0.001\end{array}$ & $\begin{array}{l}-0.214 \\
<0.001\end{array}$ & $\begin{array}{l}-0.298 \\
<0.001\end{array}$ & $\begin{array}{c}-0.111 \\
0.033\end{array}$ & $\begin{array}{c}-0.144 \\
0.006\end{array}$ & $\begin{array}{l}-0.150 \\
0.006\end{array}$ & $\begin{array}{c}0.272 \\
<0.001\end{array}$ & $\begin{array}{c}-0.113 \\
0.039\end{array}$ \\
\hline SB & $\begin{array}{l}0.061 \\
0.244\end{array}$ & $\begin{array}{c}0.240 \\
<0.001\end{array}$ & $\begin{array}{l}0.144 \\
0.006\end{array}$ & $\begin{array}{l}0.050 \\
0.338\end{array}$ & $\begin{array}{l}-0.180 \\
<0.001\end{array}$ & $\begin{array}{c}-0.033 \\
0.552\end{array}$ & $\begin{array}{l}0.162 \\
0.002\end{array}$ & $\begin{array}{c}-0.143 \\
0.009\end{array}$ \\
\hline
\end{tabular}

Significant correlations $(p \leq 0.05)$ are in bold.

[UF: urinary function; UB: urinary bother; SF: sexual function; SB: sexual bother; RP: radical prostatectomy] 
Table 3: Multivariate analysis of the whole study sample with logistic regression model (forward, stepwise variable entry)

\begin{tabular}{|c|c|c|c|c|c|c|c|c|}
\hline \multirow[b]{2}{*}{$\stackrel{r}{p-v a l u e}$} & \multicolumn{3}{|c|}{ Timing } & \multicolumn{3}{|c|}{ Tumor characteristics } & \multirow[t]{2}{*}{ Nerve-sparing } & \multirow{2}{*}{$\begin{array}{c}\text { Hormone } \\
\text { therapy }\end{array}$} \\
\hline & Age at RP & $\begin{array}{l}\text { Follow-up } \\
\text { duration }\end{array}$ & Age at follow-up & PSA & T-stage & Gleason score & & \\
\hline UF & 1 & 1 & $\begin{array}{l}-0.609 \\
0.024\end{array}$ & $\begin{array}{l}-3.557 \\
0.163\end{array}$ & $\begin{array}{l}-3.103 \\
0.163\end{array}$ & $\begin{array}{l}-2.878 \\
0.072\end{array}$ & I & $\begin{array}{l}-5.607 \\
0.056\end{array}$ \\
\hline UB & I & 1 & I & $\begin{array}{l}-2.944 \\
0.207\end{array}$ & $\begin{array}{l}-4.161 \\
0.051\end{array}$ & $\begin{array}{l}-2.272 \\
0.125\end{array}$ & $\begin{array}{l}2.774 \\
0.046\end{array}$ & $\begin{array}{l}-3.718 \\
0.189\end{array}$ \\
\hline SF & $\begin{array}{c}-1.304 \\
0.617\end{array}$ & $\begin{array}{c}-0.229 \\
0.302\end{array}$ & $\begin{array}{l}0.176 \\
0.946\end{array}$ & $\begin{array}{l}-1.104 \\
0.601\end{array}$ & $\begin{array}{c}-4.264 \\
0.024\end{array}$ & $\begin{array}{l}-2.106 \\
0.110\end{array}$ & $\begin{array}{l}3.783 \\
0.004\end{array}$ & $\begin{array}{c}-4.259 \\
0.044\end{array}$ \\
\hline SB & l & $\begin{array}{c}0.290 \\
<0.001\end{array}$ & $\begin{array}{l}0.272 \\
0.336\end{array}$ & 1 & $\begin{array}{c}-4.852 \\
0.018\end{array}$ & I & $\begin{array}{c}5.101 \\
<0.001\end{array}$ & $\begin{array}{c}-7.205 \\
0.076\end{array}$ \\
\hline
\end{tabular}

Significant results $(p \leq 0.05)$ are in bold.

[UF: urinary function; UB: urinary bother; SF: sexual function; SB: sexual bother; RP: radical prostatectomy. [/: Not included for the multivariate analyses]]

enced by timing or tumor characteristics (Table 4). On the contrary, age at follow-up and pathological stage negatively affected SF on both univariate and multivariate analysis.

\section{Differences between NS without HT and non-NS or NS with HT at interval follow-up}

We analyzed differences between patients who underwent a nerve sparing procedure without HT and non NS or NS with HT at 4 different follow up intervals. No differences in UF, UB and SB were noted between Group A and Group B subjects. As expected, patients treated with bilateral nerve sparing prostatectomy, without hormone presented better SF and SB scores in each time point (SF: NS without HT: 5 yy: 34,61, 6-7 yy: 27,78, 8-9 yy: 12,60, $\geq 10$ yу: 15,77 . NNS or NS with HT: 5 yy: 17,06, 6-7 yy: 12,97, 8-9 yy: $8,71, \geq 10$ yy: 7,42. SB: NS without HT: 5 yy 78,26, 6-
7 yy: 77,78 уy, $8-9$ yy: $83,75, \geq 10$ yy: 91,07 . NNS or NS with HT: 5 yy 64,19, 6-7 yy: 63,86, 8-9 yy: 73,36, $\geq 10$ yy: $82,20)$. Furthermore, subjects who underwent NS-RP without HT reported significantly higher SF scores 5-7 years postoperatively compared with Group B subjects [See Figure 1].

The high urinary function and bother scores in the NS without HT group at follow up 8-9 years (see Figure 1), can be explained by the low number of patients (20), with the consequent lack of worse urinary outcomes.

\section{Correlation between symptoms and bother at interval follow- up in Group A subjects}

For the analysis of correlation between symptoms and bother at 4 different follow up intervals in Group A subjects, as shown in Figure 2, our subjects reported similar

Table 4: Univariate and multivariate analyses of subjects treated with nerve-sparing RP without hormone treatment.

\begin{tabular}{|c|c|c|c|c|c|c|}
\hline \multirow[b]{2}{*}{$\underset{\text { p-value }}{r}$} & \multicolumn{3}{|c|}{ Timing } & \multicolumn{3}{|c|}{ Tumor characteristics } \\
\hline & Age at RP & Follow-up duration & Age at follow-up & PSA & T-stage & Gleason score \\
\hline SF* & $\begin{array}{l}-0.204 \\
0.050\end{array}$ & $\begin{array}{l}-0.184 \\
0.077\end{array}$ & $\begin{array}{c}-0.258 \\
0.012\end{array}$ & $\begin{array}{l}0.053 \\
0.612\end{array}$ & $\begin{array}{l}-0.207 \\
0.046\end{array}$ & $\begin{array}{l}-0.096 \\
0.359\end{array}$ \\
\hline SB* & $\begin{array}{l}0.098 \\
0.350\end{array}$ & $\begin{array}{l}0.161 \\
0.124\end{array}$ & $\begin{array}{l}0.143 \\
0.170\end{array}$ & $\begin{array}{l}-0.064 \\
0.543\end{array}$ & $\begin{array}{l}-0.015 \\
0.889\end{array}$ & $\begin{array}{l}-0.031 \\
0.771\end{array}$ \\
\hline SF\# & $\begin{array}{l}1.841 \\
0.303\end{array}$ & I & $\begin{array}{l}-3.138 \\
0.056\end{array}$ & I & $\begin{array}{c}-12.530 \\
0.027\end{array}$ & 1 \\
\hline
\end{tabular}

Significant results $(\mathrm{p} \leq 0.05)$ are in bold.

[SF: sexual function; SB: sexual bother./: Not included for the multivariate analyses] 

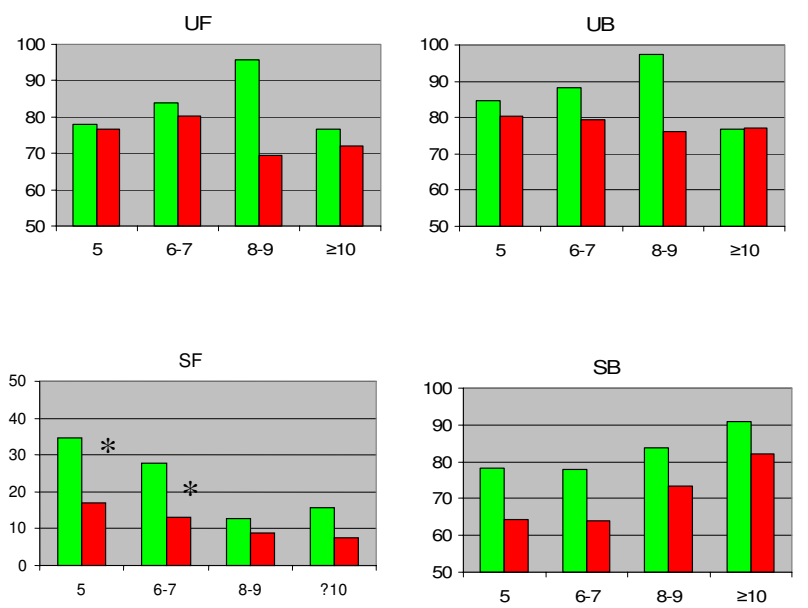

Figure I

Mean UF, UB, SF, and SB scores in subjects who underwent NS-RP without HT (Group A - green bars) and non-NS-RP or NS-RP with HT subjects (Group B - red bars), stratified according to years of follow up. UF: urinary function; UB: urinary bother; SF: sexual function; SB: sexual bother. [* $p<0.05]$.

UF and UB scores. Moreover, correlation coefficients between UF and UB scores were very similar at each of the 4 follow-up intervals. Increased follow-up duration was characterized by a progressive deterioration in SF and an improvement in SB, with the consequent dissociation of the correlation between SF and SB from 8 to 10 years after RP.

\section{Discussion}

Urinary and sexual outcomes following RP may differ by age: younger men usually have better preservation of urinary and sexual function after RP, with less bother compared to older men [12]. Higher baseline urinary and sexual function scores among younger men may drive their superior age-related outcomes [13]. Furthermore, urinary and sexual function usually worsens with age [14]: in a population-based study on long-term prostate cancer survivors, urinary incontinence and erectile dysfunction occurred more often among post-prostatectomy patients compared with the regular population, differences that cannot be explained merely by age [15]. In our study, worse UF was most common in older men several years after surgery. In particular, age at follow-up had the strongest association with postoperative incontinence, all other covariates held constant. In addition, after NS-RP without HT, follow-up age was negatively associated with erectile function: these older men reported erectile dysfunction independent of age at the time of RP and followup duration. Patients selected for NS-RP who did not require subsequent HT were essentially cancer-free; age at follow-up was the foremost determinant for sexual func- tion. Among the entire cohort, longer disease-free interval after surgery seems to be associated with reduced sexual bother independent of patient age. The absence of biochemical failure several years after RP may allow better tolerance of postoperative erectile dysfunction.

RP in locally advanced prostate cancer (pT3) offers the potential for cancer control with or without additional treatment [16]. In a retrospective study on RP performed in high risk prostate cancer, Catalona reported a preservation of continence and potency in $92 \%$ and $64 \%$ of cases respectively [17]. Furthermore, Zincke confirmed the good disease-free outcomes in long-term follow-up, and reported a complication rate in $\mathrm{T} 3$ patients similar to that among patients with T2 Pca [18]. The Department of Urology of the University of Florence is a centre of excellence for advanced (pT3) prostate cancer $[19,20]$. This can explain the high rate of pT3 patients and the low rate of nerve sparing procedure of the whole population, compared to other centers experience. In our study, we confirmed a similar continence rate between low and high stage PCa patients. Moreover, more advanced stage was associated with worse sexual outcomes. Among our entire cohort, this seems to be due to the selection of the majority of these patients for non-NS-RP in those with cT3 Pca. The negative association between stage and sexual function among Group A patients (NS-RP without HT) may relate to more difficult dissection of the neurovascular bundle from the prostate capsule and the avoidance of an intrafascial dissection of the periprostatic neurovascular bundle.

Consistent with analyses of QoL outcomes among RP patients, the potency rates reported herein after NS-RP without HT were associated with reduced sexual bother. The sexual function outcomes among this group were superior to those undergoing non-NS-RP and NS-RP with HT up to 7 years after surgery (see figure 1, panel SF). Beyond 7 years postoperatively, age-related erectile dysfunction may explain the equilibration of sexual function outcomes between these two patient groups. Moreover, our population resulted in general less bothered than other populations such as reported in literature [21]. This data can be easily explain by the remarkable impact on the disease free status (PSA $<0.2 \mathrm{ng} / \mathrm{mL}$ ) at long term follow up time ( $>5$ years) of our patients: the conviction of an effective cancer control allow a better acceptance of sexual comorbidities.

We found a non-significant trend toward better continence after NS-RP. Several authors have reported that NS confers improved postoperative urinary continence $[22,23]$. The lack of a correlation in our series may be related to the advanced age at follow-up and the consequent age-related incontinence of our cohort. Interest- 

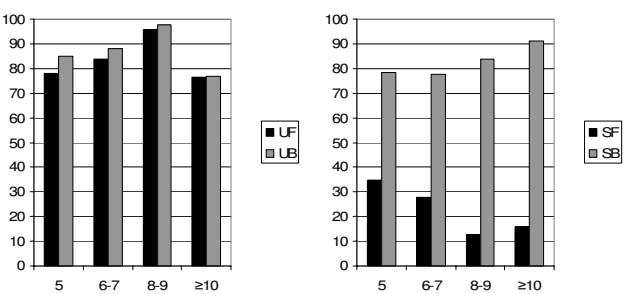

\begin{tabular}{|c|c|c|c|c|}
\hline \multirow[b]{2}{*}{$\begin{array}{c}\mathrm{r} \\
\text { p-value }\end{array}$} & \multicolumn{4}{|c|}{ Years after RP } \\
\hline & 5 & $6-7$ & $8-9$ & $\geq 10$ \\
\hline UF - UB & $\begin{array}{c}0.877 \\
<0.0001\end{array}$ & $\begin{array}{c}0.959 \\
<0.001\end{array}$ & $\begin{array}{c}0.922 \\
<0.001\end{array}$ & $\begin{array}{c}0.993 \\
<0.001\end{array}$ \\
\hline $\mathrm{SF}-\mathrm{SB}$ & $\begin{array}{l}0.412 \\
0.051\end{array}$ & $\begin{array}{l}0.492 \\
0.002\end{array}$ & $\begin{array}{l}0.281 \\
0.230\end{array}$ & $\begin{array}{c}-0.132 \\
0.651\end{array}$ \\
\hline
\end{tabular}

Figure 2

Comparison of function and bother among Group A subjects at interval follow-up. The table reports Pearson correlation coefficients and $\mathrm{p}$-values assessing the correlation between function and bother. Non-significant results $(p>$ 0.05 ) are in bold. UF: urinary function; UB: urinary bother; SF: sexual function; SB: sexual bother; RP: radical prostatectomy.

ingly, men treated with NS-RP had significantly less urinary bother compared with men who underwent nonNS-RP, independent of the degree of urinary incontinence. Urinary bother may correlate more closely with the severity of storage urinary symptoms, more common after external beam radiation therapy or brachytherapy, rather than with the degree of urinary incontinence [24].

Finally, the analyses of Group A men stratified by followup duration demonstrated that, while minimal urinary symptoms were associated with increased distress related to those symptoms, the progressive development of erectile dysfunction is well tolerated 8 or more recurrence-free years after surgery. This confirms that minimal urinary incontinence continues to be poorly tolerated even after several years of good cancer control, while erectile dysfunction progressively diminishes as a problem in the daily life of long-term disease-free survivors.

Our study presents several limitations. First of all, we did not include some factors that may have biased our outcomes, such as marital status, education level, employment status, and income. We were, however, able to account for factors known to have a substantial influence on postoperative QoL, such as patient age, pathological features of the PCa, NS status, and the administration of hormone therapy. Moreover, all recruited men underwent RP in centers of excellence by skilled urologists. Thus, our patient population and QoL outcomes may be not repre- sentative of the general population. Furthermore, we did not evaluate generic and general oncological QoL with validated instruments such as the Medical Outcomes Study Short Form-12 or the European Organization for Research and Treatment of Cancer QOL-30. Finally, our findings have the inherent limitations of a retrospective study, most prominently a lack of baseline QoL data.

\section{Conclusion}

We demonstrated that long-term RP outcomes follow a distinct QoL trajectory. Older men develop worse urinary continence independent of age at time of surgery or follow-up duration. Pathological stage was an important determinant of postoperative QoL outcomes, affecting both urinary and sexual function. Beyond 8 years after NSRP without HT, patients noted substantial sexual dysfunction, but, surprisingly, they were minimally sexually bothered. These results contribute to the clinician's ability to counsel long-term prostate cancer survivors.

\section{Abbreviations}

RP: Radical Prostatectomy; NS: Nerve sparing; HT: Hormone Treatment; QOL: Quality of life; F.up: Follow up; UCLA-PCI: University of California, Los Angeles, Prostate Cancer Index; UF: Urinary Function; SF: Sexual Function; UB: Urinary Bother; SB: Sexual Bother;

\section{Competing interests}

The authors declare that they have no competing interests.

\section{Authors' contributions}

$M G$, AS have made substantial contributions to conception and design. ML, AM, MAR, SS, VV, AR, CA, FV, METM were involved in the acquisition of data. LM and VV have made significant assistance in the interpretation of data. JLG has been involved in drafting the manuscript or revising it critically for important intellectual content. GC and MC have given final approval of the version to be published. Each author should have participated sufficiently in the work to take public responsibility for appropriate portions of the content.

\section{Acknowledgements}

The authors thank Prof. Mark Litwin for his suggestions on improvements for data analysis and presentation and for revising the manuscript.

\section{References}

I. Miller DC, Saigal CS, Litwin MS: Urologic Diseases in America Project. The demographic burden of urologic diseases in America. Urol Clin N Am 2009, 36(I): I I-27.

2. Kundu SD, Roehl KA, Eggener SE, Antenor JA, Han M, Catalona WJ: Potency, continence and complications in 3,477 consecutive radical retropubic prostatectomies. J Urol 2004, I72(6Pt I):2227-3I.

3. Penson DF, Litwin MS, Aaronson NK: Health related quality of life in men with prostate cancer. J Urol 2003, 169(5):1653-61. 
4. Schroeck FR, Krupski TL, Sun L, Albala DM, Price MM, Polascik TJ, Robertson CN, Tewari AK, Moul JW: Satisfaction and regret after open retropubic or robot-assisted laparoscopic radical prostatectomy. Eur Urol 2008, 54(4):785-93.

5. Savera AT, Kaul S, Badani K, Stark AT, Shah NL, Menon M: Robotic radical prostatectomy with the "Veil of Aphrodite" technique: histologic evidence of enhanced nerve sparing. Eur Urol 2006, 49(6): 1065-73.

6. Stanford JL, Feng Z, Hamilton AS, Gilliland FD, Stephenson RA, Eley JW, Albertsen PC, Harlan LC, Potosky AL: Urinary and sexual function after radical prostatectomy for clinically localized prostate cancer: the Prostate Cancer Outcomes Study. JAMA 2000, 283(3):354-60.

7. Rogers CG, Su LM, Link RE, Sullivan W, Wagner A, Pavlovich CP. Age stratified functional outcomes after laparoscopic radical prostatectomy. J Urol 2006, I 76(6 Pt I):2448-52.

8. Sacco E, Prayer-Galetti T, Pinto F, Fracalanza S, Betto G, Pagano F, Artibani $W$ : Urinary incontinence after radical prostatectomy: incidence by definition, risk factors and temporal trend in a large series with a long-term follow-up. BJU Int 2006, 97(6):|234-4|.

9. Mettlin C], Murphy GP, Sylvester J, McKee RF, Morrow M, Winchester DP: Results of hospital cancer registry surveys by the American College of Surgeons: outcomes of prostate cancer treatment by radical prostatectomy. Cancer 1997, 80(9): $|875-8|$.

10. Gacci M, Livi L, Paiar F, Detti B, Litwin MS, Bartoletti R, Giubilei G, Cai T, Mariani M, Carini M: : Quality of life after radical treatment of prostate cancer: validation of the italian version of the University of California-Los Angeles Prostate Cancer Index. Urology 2005, 66:338-43.

II. Briganti A, Salonia A, Gallina A, Chun FK, Karakiewicz PI, Graefen M, Huland H, Rigatti P, Montorsi F: Management of erectile dysfunction after radical prostatectomy in 2007. World ] Urol 2007 25:143-8.

12. Karakiewicz P, Tanguay S, Kattan M, Elhilali M, Aprikian A: Erectile and urinary dysfunction after radical prostatectomy for prostate cancer in Quebec: a population based study of 2415 men. Eur Urol 2004, 46: 188

13. Wright J, Lin D, Cowan J, Carroll P, Litwin M, the caPSURE Investigators: Prostate cancer and prostatic disease. 2008, I I:67-73.

14. Jonler M, Moon T, Brannan W, Stone NN, Heisey D, Bruskewitz RC: The effect of age, etnicity and geografical location on impotence and quality of life. $\mathrm{Br} J$ Urol 1995, 75:65I.

15. Mols F, Korfage IJ, Vingerhoets AJ, Kil PJ, Coebergh JW, Essink-Bot ML, Poll-Franse LV van de: Bowel, urinary and sexual problems among long-term prostate cancer survivors: a populationbased study. Int J Radiat Oncol Biol Phys 2009, 73(I):30-8.

16. Van Poppel H, Joniau S: An analysis of radical prostatectomy in advanced stage and high-grade prostate cancer. Eur Urol 2008 , 53:253-59.

17. Loeb S, Smith ND, Roehl KA, Catalona WJ: Intermediate-term potency, continence and survival outcomes of radical prostatectomy for clinically high-risk or locally advanced prostate cancer. Urology 2007, 69: I I 70-5.

18. Ward JF, Slezak JM, Blute M, Bergstralh E], Zincke H: Radical prostatectomy for clinically advancer (cT3) prostate cancer since the advent of prostate-specific antigen testing: I5-years outcomes. BJU Int 2005, 95:75I-6.

19. Serni S, Masieri L, Minervini A, Lapini A, Nesi G, Carini M: : Cancer progression after anterograde radical prostatectomy for pathologic Gleason score 8 to 10 and influence of concomitant variables. Urology 2006, 67(2):373-8.

20. Serni S, Masieri L, Lapini A, Nesi G, Carini M: A low incidence of positive surgical margins in prostate cancer at high risk of extracapsular extension after a modified anterograde radical prostatectomy. BJU Int 2004, 93(3):279-83.

21. Meyer JP, Gillatt DA, Lockyer R, Macdonagh R: : The effect of erectile dysfunction on the quality of life of men after radical prostatectomy. BJU Int 2003, 92(9):929-3I.

22. Marien TP, Lepor $H$ : Does a nerve sparing technique or potency affect continence after open radical retropubic prostatectomy? BJU Int 2008, I02(I I):I58I-4.

23. Penson DF, McLerran D, Feng Z, Li L, Albertsen PC, Gilliland FD, Hamilton A, Hoffman RM, Stephenson RA, Potosky AL, Stanford JL: 5-years urinary and sexual outcomes after radical prostatectomy: results from the PCOS. J Urol 2005, I73:170I-1705.

24. Miller DC, Sanda MG, Dunn RL, Montie JE, Pimentel H, Sandler HM, McLaughlin WP, Wei JT: Long-term outcomes among localized prostate cancer survivors: health-related quality-of-life changes after radical prostatectomy, external radiation, and brachytherapy. J Clin Oncol 2005, 23(1 2):2772-80.
Publish with Biomed Central and every scientist can read your work free of charge

"BioMed Central will be the most significant development for disseminating the results of biomedical research in our lifetime. "

Sir Paul Nurse, Cancer Research UK

Your research papers will be:

- available free of charge to the entire biomedical community

- peer reviewed and published immediately upon acceptance

- cited in PubMed and archived on PubMed Central

- yours - you keep the copyright 